\title{
Mengawal Tumbuh Kembang Balita dengan Optimalisasi Stimulasi Perkembangan Masa Usia Dini di Masa Pandemi Covid-19
}

\author{
Dian Furwasyih, Dewi Susilawati, Rahmayeni Supri, Reca Yolandha \\ E mail: deemidwife@gmail.com \\ Program Studi Kebidanan Program Sarjana dan Pendidikan Profesi Bidan Program Profesi \\ Jalan Jamal Jamil Pondok Kopi Siteba Padang \\ Telp/Fax (0751) 442295
}

\begin{abstract}
Abstrak
Pemantauan tumbuh kembang, adalah suatu kegiatan untuk menemukan secara dini adanya penyimpangan pertumbuhan (status gizi kurang atau buruk, anak pendek), penyimpangan perkembangan (terlambat bicara), dan penyimpangan mental emosional anak (gangguan konsentrasi dan hiperaktif). Pesatnya pertumbuhan dan perkembangan pada 1.000 hari pertama kehidupan membuat pemantauan tumbuh kembang anak sangat penting pada usia ini. 1.000 hari pertama kehidupan dihitung mulai dari saat pembuahan di dalam rahim ibu sampai anak berusia 2 tahun. Pada anak usia 2 tahun tinggi badannya sudah mencapai setengah dari tinggi orang dewasa dan perkembangan otaknya sudah mencapai 80\% dari otak dewasa. Sejak Maret 2020, Indonesia dilanda oleh pandemi COVID-19. Hal ini mengakibatkan kegiatan posyandu di berbagai wilayah di Indonesia dihentikan sementara waktu. Kekhawatiran akan kondisi pandemi membuat orang tua takut untuk membawa balita ke klinik maupun puskesmas. Salah satu langkah paling mudah dilakukan ibu maupun pengasuh untuk menstimulasi tumbuh kembang balita di rumah adalah dengan pijat bayi. Solusi Dan target Luaran yang ditawarkan pada kegiatan ini adalah edukasi stimulasi tumbuh kembang, demonstrasi pijat bayi, dan pendampingan ibu balita untuk pijat bayi sebanyak 2x sebulan Target Luaran kegiatan publikasi artikel di jurnal Pengabdian Masyarakat, publikasi media cetak, dan peningkatan keberdayaan masyarakat dan penguatan pengetahuan dan pengembangan kebiasaan masyarakat dalam berperilaku sehat.
\end{abstract}

Kata kunci: stimulasi tumbuh kembang; pijat bayi; pandemi COVID-19

\begin{abstract}
Monitoring of growth and development is an activity to detect early growth irregularities (malnutrition or poor nutritional status, short children), developmental deviations (late speaking), and mental emotional disorders (impaired concentration and hyperactivity). The rapid growth and development in the first 1,000 days of life makes monitoring of child development very important at this age. The first 1,000 days of life are counted from the time of conception in the mother's womb until the child is 2 years old. In children aged 2 years, the height has reached half of the adult's height and the brain development has reached $80 \%$ of the adult brain. Since March 2020, Indonesia has been hit by the COVID-19 pandemic. This resulted in the temporary suspension of posyandu activities in various regions in Indonesia. Fears of a pandemic condition make parents afraid to bring toddlers to clinics and puskesmas. One of the easiest steps for mothers and caregivers to take to stimulate the growth and development of toddlers at home is baby massage. Solutions and targets The outputs offered in this activity are growth and development stimulation education, infant massage demonstrations, and assistance to mothers of toddlers for infant massage for $2 \mathrm{x}$ a month. The output targets are publication of articles in the journal Community Service, print media publications, and increasing community empowerment and strengthening knowledge and developing community habits in healthy behavior
\end{abstract}

Keywords: stimulation of growth and development; baby massage; the COVID-19 pandemic. 


\section{Pendahuluan}

Pemantauan tumbuh kembang, adalah suatu kegiatan untuk menemukan secara dini adanya penyimpangan pertumbuhan (status gizi kurang atau buruk, anak pendek), penyimpangan perkembangan (terlambat bicara), dan penyimpangan mental emosional anak (gangguan konsentrasi dan hiperaktif). Pesatnya pertumbuhan dan perkembangan pada 1.000 hari pertama kehidupan membuat pemantauan tumbuh kembang anak sangat penting pada usia ini. 1.000 hari pertama kehidupan dihitung mulai dari saat pembuahan di dalam rahim ibu sampai anak berusia 2 tahun. Pada anak usia 2 tahun tinggi badannya sudah mencapai setengah dari tinggi orang dewasa dan perkembangan otaknya sudah mencapai $80 \%$ dari otak dewasa ${ }^{(1)}$ Pada anak usia

Pemantauan tumbuh kembang, adalah suatu kegiatan untuk menemukan secara dini adanya penyimpangan pertumbuhan (status gizi kurang atau buruk, anak pendek), penyimpangan perkembangan (terlambat bicara), dan penyimpangan mental emosional anak (gangguan konsentrasi dan hiperaktif). Pemantauan tumbuh kembang bertujuan untuk mengetahui pertumbuhan dan perkembangan anak serta menemukan secara dini adanya gangguan tumbuh kembang sehingga dapat ditindaklanjuti segera agar hasilnya lebih baik. ${ }^{(1)}$ Kegiatan pemantauan ini biasanya dilakukan di posyandu oleh petugas kesehatan. Sejak Maret 2020, Indonesia dilanda oleh pandemi COVID-19.(2) Hal ini mengakibatkan kegiatan posyandu di berbagai wilayah di Indonesia dihentikan sementara waktu.
Kekhawatiran akan kondisi pandemi membuat orang tua takut untuk membawa balita ke klinik maupun puskesmas. Salah satu langkah paling mudah dilakukan ibu maupun pengasuh untuk menstimulasi tumbuh kembang balita di rumah adalah dengan pijat bayi. Berdasarkan permasalahan diatas, penulis melakukan kegiatan edukasi kepada orang tua balita tentang stimulasi tumbuh kembang balita di usia dini pada masa pandemi COVID-19. Dalam edukasi ini, penulis juga mendemonstrasikan teknik pijat bayi agar orang tua bisa melakukan di rumah.

\section{Metode}

Hasil identifikasi masalah pada analisis situasi di atas maka solusi atau bentuk intervensi yang ditawarkan ialah dengan melakukan edukasi tentang stimulasi dan demonstrasi pijat bayi dengan kegiatan sebagai berikut : 1 . Kegiatan edukasi tentang stimulasi tumbuh kembang bayi dan balita pada ibu balita di Klinik MERCUBAKTIJAYA Padang 2. Kegiatan demonstrasi pijat bayi pada ibu balita 3. Rencana tindak lanjut : Pendampingan ibu balita setiap 2x sebulan untuk melakukan pijat bayi di Klinik MERCUBAKTIJAYA Padang sesuai jadwal yang disepakati 4 . Tim pengusul melibatkan peran serta mahasiswa dalam membantu kelancaran program yang akan dilaksanakan serta dapat menambah wawasan mahasiswa untuk menerapkan ilmunya secara langsung di lapangan. Rancangan mekanisme pelaksanaan kegiatan ini dilakukan dengan mengadopsi langkahlangkah action research yang terdiri dari 4 (empat) tahapan, yaitu: perencanaan, tindakan, 
observasi dan evaluasi, dan refleksi. $^{(4)}$

\section{Hasil dan Pembahasan}

Kegiatan ini dilaksanakan tanggal 16 Januari 2021 di Klinik MERCUBAKTIJAYA Padang. Peserta yang hadir ada 5 pasang orang tua dengan 8 balita. Kegiatan diawali dengan pre test kepada ibu balita tentang pengetahuan ibu tentang stimulasi tumbuh kembang dan pijat bayi. Pre test berlangsung selama 10 menit. Kemudian, dilanjutkan dengan sesi 1 yaitu edukasi tentang stimulasi tumbuh kembang anak usia dini 1000 hari pertama kehidupan. Sesi 1 berlangsung selama 15 menit. Sesi 2 adalah demonstrasi pijat bayi yang didampingi oleh tim pengabdi dan tim klinik MERCUBAKTIJAYA Padang. Sesi 2 berlangsung selama 1 jam. Selanjutnya, dilakukan post test dengan soal yang sama dengan pre test untuk menilai perbedaan skor pengetahuan sebelum dan sesudah kegiatan.

Hasil dari pre test tersebut adalah:

Tabel 3.1 Tingkat Pengetahuan Orang Tua tentang Stimulasi Tumbuh Kembang Balita Sebelum Penyuluhan

\begin{tabular}{clcc}
\hline No & Kategori & Jml & $\%$ \\
\hline 1 & Tinggi & 2 & 20 \\
\hline 2 & Sedang & 3 & 30 \\
\hline 3 & Rendah & 5 & 50 \\
\hline
\end{tabular}

Tabel 3.1 menjelaskan bahwa separuh dari orang tua $(50 \%)$ masih memiliki tingkat pengetahuan rendah tentang stimulasi tumbuh kembang balita. Hal ini dapat disebabkan karena rendahnya minat orang tua untuk mencari informasi tentang stimulasi tumbuh kembang balita.
Tabel 3.2 Tingkat Pengetahuan Orang Tua tentang Stimulasi Tumbuh Kembang Balita Setelah Penyuluhan

\begin{tabular}{clcc}
\hline No & Kategori & Jml & $\%$ \\
\hline 1 & Tinggi & 6 & 60 \\
\hline 2 & Sedang & 3 & 30 \\
\hline 3 & Rendah & 1 & 10 \\
\hline
\end{tabular}

Tabel 3.2 menjelaskan bahwa lebih dari separuh orang tua $(60 \%)$ memiliki tingkat pengetahuan tinggi tentang stimulasi tumbuh kembang balita. Dari tabel 3.2 juga terlihat adanya 15 peningkatan pengetahuan orang tua tentang stimulasi tumbuh kembang balita setelah diberi penyuluhan.

Berikut adalah dokumentasi kegiatan :

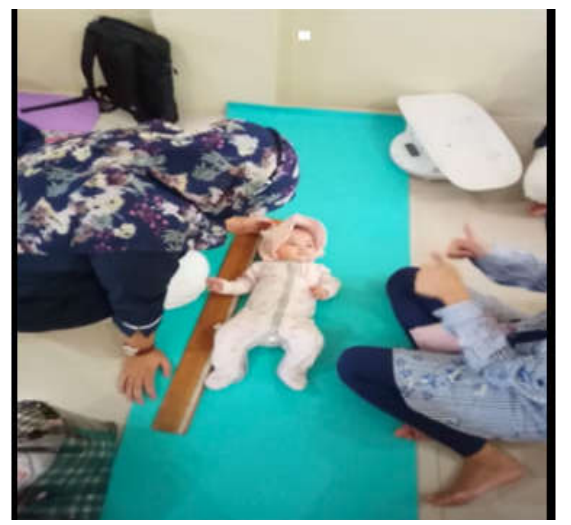

Gambar 3.1. Dokumentasi kegiatan

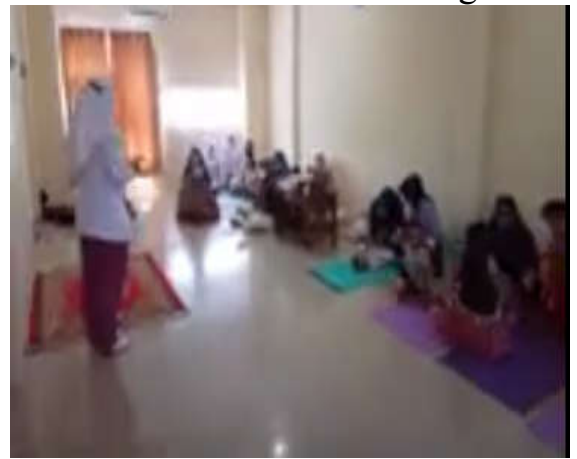

Gambar 3.2. Dokumentasi kegiatan 


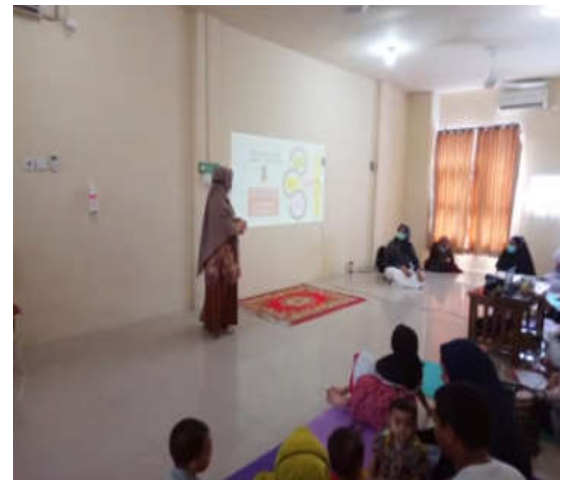

Gambar 3.3. Dokumentasi kegiatan

\section{Kesimpulan}

\begin{abstract}
Kegiatan ini memberikan dampak positif terhadap peningkatan pengetahuan audiens tentang stimulasi tumbuh kembang balita sebesar $60 \%$. Dapat direkomendasikan kepada audiens agar selalu melaksanakan anjuran yang telah disampaikan pada saat penyampaian materi dalam kegiatan ini tentang cara menjaga stimulasi perkembangan usia dini di masa pandemi COVID-19 sehingga tetap dapat mengawal tumbuh kembang balita dengan optimal.
\end{abstract}

\section{Daftar Pustaka}

[1] "1.000 Hari Pertama Kehidupan Dalam Tumbuh Kembang Anak" - Kanal Pengetahuan FKKMK UGM [Internet]. Kanal Pengetahuan UGM. 2020 [cited 2021 Jan 21]. Available from: https://kanalpengetahuan.fk.ug m.ac.id/1-000-haripertamakehidupan-dalamtumbuh-kembang-anak/
[2] Ridlo IA, "Pandemi COVID19 dan Tantangan Kebijakan Kesehatan Mental di Indonesia," $J$ Psikol dan Kesehat Ment, vol. 5, no. 2, pp. 155-64, 2020.

[3] A. Syamsudin, Undang undang Republik Indonesia nomor 35 tahun 2014 tentang Perubahan atas Undang undang no 23 tahun 2002 tentang Perlindungan Anak. p.561-5. 2014.

[4] UNICEF Division of Communication, "The Child Friendly School manual," The Child Friendly School manual, 2006.

http://www.unicef.org/publicat ions/files/Child_Friendly_Scho ols_Manual_EN_040809.pdf.

[5] I. Indriyani, "Pengaruh Pijat Bayi," vol. 3, pp. 2010-3, 2015. 